2017-02-08

"It was amazing to see our projects come to life!" Developing affective learning during geography fieldwork through tropophilia

\author{
Holton, Mark
}

http://hdl.handle.net/10026.1/8732

10.1080/03098265.2017.1290592

Journal of Geography in Higher Education

Taylor \& Francis (Routledge)

All content in PEARL is protected by copyright law. Author manuscripts are made available in accordance with publisher policies. Please cite only the published version using the details provided on the item record or document. In the absence of an open licence (e.g. Creative Commons), permissions for further reuse of content should be sought from the publisher or author. 


\title{
"It was amazing to see our projects come to life!" Developing affective learning during geography fieldwork through tropophilia
}

\author{
Holton, Mark (2017) - School of Geography, Earth, and Environmental Sciences, \\ Plymouth University
}

Accepted - 21 September 2016 (embargo until 21 March 2018)

Cite this article: Holton, M. (2017). "It was amazing to see our projects come to life!" Developing affective learning during geography fieldwork through tropophilia. Journal of Geography in Higher Education. DOI: 10.1080/03098265.2017.1290592

\section{Abstract}

This research, conducted with groups of undergraduate students before and after a European fieldwork exercise, critically examines the pedagogic value of fieldwork and its ability to provide students with transferable skills. This is achieved using Anderson and Erskine's (2014) lens of tropophilia - the aesthetic connection between people and place to explore the influence of 'being' in the field upon affective learning. In doing so, this research suggests (1) that encouraging students to recognise how their own affective skills may influence the types of knowledge(s) that are produced on fieldtrips and (2) that people-place connections have the ability to inspire students to become more self-reflexive about their position(s) as learners.

\section{Keywords}

Affective domain; Mobility; Fieldwork; Place; Affective learning; Tropophilia

\section{Introduction}


Fieldwork is an important component in the geographer's suite of tools (Fuller et al., 2006; Stokes et al., 2011) and has been a fundamental part of the teaching framework for many years (Fuller, 2006). The benefits of fieldwork are self-evident but, as a recent special issue in the pages of this journal suggests (Glass, 2015), fieldwork does not come without its fair share of challenges, both in terms of practice and in long-term development. In pedagogic terms fieldwork removes students from the restrictions of the classroom and places them directly in the environment they are studying in (Dummer et al., 2008). In its simplest form fieldwork can be defined as "the formal process of the study of the environment that takes place outside the classroom and that uses the environment as a learning resource" (Scott et al., 2006, p. 161). This tangible interaction between Self and place has been viewed, almost unanimously, as a vital tool for putting complex and abstract theoretical concepts into practice (Stokes et al., 2011). Beyond its pedagogic capacity fieldwork is well received by both staff and students, particularly for its immersive, technical and subject-specific value and its ability to allow students to 'skill up' with transferable skills (Wall and Speake, 2012).

These pedagogic benefits, are however, not without their critics and some scholars have accused geographers of privileging fieldwork based upon weak and naive epistemologies which equate 'real-world experience' with 'truth' (Kent et al., 1997). University open days and prospectuses all too often rush to use exotic fieldwork destinations as promotional tools to entice students, while ignoring the pedagogic reasoning behind taking students out of the classroom and placing them in the field (Herrick, 2010), perpetuating the class / field-class dichotomy. Moreover, Fuller et al. (2006) question whether fieldwork actually improves students' learning capabilities, particularly as Gold et al. (1991) have previously argued that, for all its assumed value, it remains unclear as to the actual value of fieldwork. Moreover, Fuller (2006) suggests that fieldwork experiences should be perceived as opportunities for sensing real experiences and adding value to activities that may not 
necessarily be replicable in the classroom. This presents opportunities to develop tasks that address these difficult epistemological challenges in order to transform learners' "[...] attitudes towards ways of learning in and about geography more broadly" (Herrick, 2010, p. 115 , emphasis in original).

A novel way of approaching this is through Anderson and Erskine's (2014) understanding of 'tropophilia'. Tropophilia refers to "[an] individual's need to move and be moved and to be stimulated and challenged in terms of their relations to place" (ibid, p. 135, emphasis in original). This mobility-focused approach to place-attachment is an extension of Tuan's (1974) concept of topophilia which is concerned with the confluence of a person's affective ties with their material environment and explores how individuals develop positive connections to places. Tropophilia and topophilia share links with notions of sense of place which emphasise how we may interpret the aesthetic qualities of an environment through direct experience with it (Hay, 1998). Moreover, in contrast to topophilia's valuing of stasis and familiarity, tropophilia's understanding of mobility emphasises a desire for change upon our appreciation of the world (Anderson, 2015). Incorporating these 'platial' notions into undergraduate fieldwork, particularly the reflexivity between people and places, will be useful in helping novice field researchers make sense of the skills they acquire while out in the field. Moreover, tropophilia promotes self-reflexive mobilities and identity transformations (Anderson and Erskine, 2016) and this paper examines how this extends to experiences of learning transformations. For example, how the field-class may become enlivened through the action of being mobile, of moving from one location to another and being directly involved in the outcomes of such movements, stimulating richer ways of enabling learning. This presents exciting new opportunities to explore how fieldwork experiences might encourage students to view the world and their learning in different terms and go some way in problematising the field / classroom binaries discussed earlier. To achieve this, the research examines (1) students' abilities to recognise how affective 
skills may influence the types of knowledge(s) that are produced on fieldtrips and (2) by what means people-place connections may be capable of inspiring students to become more self-reflexive about their position(s) as learners.

\section{Observation and participation}

Fieldwork activities take on many forms but are fundamentally reduced down to observation and participation. As Kent et al. (1997) point out, observational exercises are fairly straightforward to implement and deliver and require only that students be in the field. Observational exercises usually entail students taking copious amounts of notes to detail the characteristics of field environments and experiences with which to elaborate upon once returning to the classroom (Phillips and Johns, 2012). While observation may be considered inferior to active participation, McGuinness and Simm (2005) argue that, implemented effectively, such tasks can be useful assessment mechanisms to promote reflective learning. However, Marvell et al. (2013) argue that participation, and to a greater extent autonomy, stimulates more productive field-learning experiences if students take control over the collection, analysis and dissemination of data (Pawson and Teather, 2002) and thus provides transferable skills (Scheyvens et al., 2008). Hence such studentled tasks can be self-reflexive, shifting students' learning from being passive to active (Marvell et al., 2008) and encouraging interpretation, critical thinking and the sharing of ideas.

\section{Active learning}

Crucial to the success of fieldwork is a consideration of the active and participatory learning being in the field provides. As Scheyvens et al. (2008) argue active learning is typically defined as a counterpoint to passive learning whereby lecturers deliver information and students acquiesce. This didactic approach has its uses, particularly in the retention of surface knowledge and information recall, however a lack of student 
interaction rarely encourages learners to move on to develop deeper conceptual understandings of topics or to take ownership of their learning (Panelli and Welch, 2005). Kolb (1984) critiques the passive approach, suggesting that the gap between skills and knowledge can be filled through experience. Experiential learning recognises that the cyclical nature of learning - encompassing planning, doing, observing and thinking, requires students to consider how the active and reflective aspects of learning might enrich their capacity to learn effectively and broadly (Scheyvens et al., 2008). Active learning follows a constructivist approach which recognises that knowledge cannot simply be reproduced independently from the individual but is, in fact, the product of the internal knowledge of the student and the external structures which facilitate that knowledge (Biggs and Tang, 2011). Active learning has thus become a crucial model in learning development over the last thirty years, with proponents celebrating its capacity to promote students' academic skills (e.g. analysis, synthesis, evaluation, critique, application, reflexivity etc.). Marvell et al. (2013) argue that, alongside these academic skills, active learning also increases students' capacity to understand their own role within the learning process, emphasising Gibbs' (1992) point that active learning should consider the intersections between 'thinking' and 'doing', rather than simply considering them as separate entities. This presents opportunities to challenge what is considered 'static' or 'finished' knowledge (Dewey, 2007) by encouraging students to become stakeholders in their learning (Brew, 2006). However, while the deep understanding gained through active learning is preferable, it is also important that students understand what is to be learned and how (Herrick, 2010).

In the context of fieldwork, active learning has come under scrutiny with Nairn (2005) arguing that because learning is primarily shaped by a "politics of position" (p. 295), the social structures we exist in are unlikely to be influenced beyond the temporality of the field trip (Hope, 2009). Crucially, Hope (2009) argues that students' positions may often be 
reinforced by fieldwork experiences, particularly those that require them to consider difference, disadvantage or inequality. Hence, it may be too much to ask of the young, inexperienced undergraduate investigator to question their positionality as researchers to any great depth during a week-long residential field course (Marvell et al., 2013), particularly when more experienced researchers also struggle to reconcile their own positions in the field (Katz, 1994). In this sense Nairn's (2005) research problematises active, experiential learning by highlighting how the social construction of self can hinder both the production of knowledge and its transformation (Hope, 2009).

\section{Theoretical Framework}

This paper critiques the production of field-skills and knowledge through the affective learning taxonomy (Bloom, 1954; Krathwohl et al., 1964). Both Bloom and Krathwohl posited that cognitive learning is often achieved through the acquisition of knowledge and affective learning is satisfied through the emotional valuing of that knowledge (Bolin et al., 2005). While both the cognitive and affective domains are discussed here, this research focuses primarily on the development of affective learning to highlight the range of values, attitudes and behaviours (Buissink-Smith et al., 2011) and how these influence, and are influenced by, place and mobility (Simm and Marvell, 2015). Krathwohl's (1964) taxonomy identifies five hierarchical stages in the acquisition of affective skills: an ability to (1) receive information, (2) respond to interactions, (3) value such responses, (4) organise such values, and (5) internalise or commit to practice (Buissink-Smith et al., 2011). When relating this to fieldwork Hope (2009) argues that it is the relationship between direct experience, affective response and deep learning that makes fieldwork most effective in the affective domain. Notwithstanding, these theories have not been approached uncritically and Biggs and Tang (2011) have cautioned that these domains are not catchall approaches, arguing that affective learning taxonomies may not necessarily be applicable to all modes of learning. Prescriptively imposing such templates upon modules 
may produce too many outcomes, thus clouding the genuinely relevant pedagogical aspects of the learning experience.

Exploring the affective domain has, however, been highly effective in understanding skills progressions among learners in the field (Boyle et al., 2007). For example, van der Hoeven Kraft et al. (2011) explored how the intersections of various components, including self-efficacy and place attachment, greatly improved students' opportunities to maximise learning within the geosciences. This research uses a similar approach but instead explores a more 'geo-spatial' domain which examines how skills and knowledge may be [re]produced through people / place connections. Here, exposing the influences upon the intersections between the affective and cognitive domains stimulates a more heuristic understanding of fieldwork experiences. Moreover, this implies that 'being in place' may strengthen the emotional and behavioural aspects of learning by encouraging learners to recognise how affective skills may assist in applying knowledge laterally across the degree programme. Whilst this shares the environmental characteristics of van der Hoeven Kraft et al.'s. (2011) model, this design does not expect all aspects to align perfectly, but instead examines the more inherent connections between people, place and learning.

\section{Methodology}

The data for this project were collected over two consecutive academic years (2014/15 and 2015/16) as part of a UK university's second year Geography fieldtrip in which students participated in a week-long residential trip to one of two European destinations. Each trip contained a mixture of BA and BSc students and comprised an orientation day, two staff-led project days and a longer, pre-defined student-led project where groups of students collected data over a three-day period before presenting their findings on the last day of the trip. Students subscribed to two staff-led projects before the trip that were based upon a variety of geographical subjects including (among others) nature / culture binaries; 
archaeological landscapes; climate change; social resilience and creative geographies. These entailed a mixture of pre-reading, field demonstrations and active engagement. The student-led projects followed an inquiry-based model similar to Spronken-Smith and Hilton's (2009) whereby the students were asked to form small groups of 3-5 approximately six weeks prior to the trip and prepare a proposal for an original piece of research. Groups were assigned a supervisor to assist them with constructing the project as well as being available to guide them during the data collection, presentation preparation and report writing stages. The students were also encouraged through the module handbook and preparatory lectures to consider aligning their projects with the types of research methodologies they intended to employ in their dissertations.

The data were collected using 'paired questionnaires' (Boyle et al., 2007) that were circulated before and after the fieldtrips to examine the students' preconceptions and reflections of the trips. Such small-scale research, of course, comes with its limitations, particularly in terms of the expectations that students will experience significant development in affective learning from such a short trip. That said, this research demonstrates how even a short period in the field can act as a conduit for shifting from surface to engaged learning. Pairing the questionnaires allowed for more direct comparisons, making the results more consistent. For example, questions relating to subject skills were repeated but framed to identify changes in the students' perceptions and experiences (Table 1). Other questions were specific to either their preparation for, or reflection on, the trip (Boyle et al., 2007). The skills-based questions were multiple choice and the participants were encouraged to select as many categories as they liked. Participants may, of course, have felt compelled to 'parrot' the learning outcomes they were exposed to in the module handbook, and some of these were certainly used as choices in the surveys along with other more specific choices that the students probably had not connected with fieldwork experiences. To mitigate this, a varied range of open and 
closed questioning styles were employed to reduce the potential for participants giving impassive responses (Secor, 2010). Of course, this structured, a-priori questioning meant there was less freedom for the students to give spontaneous answers (Punch, 2014) and some might argue that a quantitative summary approach misses the nuance and detail of affective learning that could be effectively captured using qualitative methods. To ameliorate this comment boxes were provided to encourage the students to expand upon the responses they gave. As the research was conducted when the students were experiencing several key deadlines this technique required less commitment from them than more in-depth qualitative methods might, enabling a fuller dataset to be collected. These qualitative responses also helped in contextualising the quantitative data and developing themes within the analysis. Participants were recruited from the module during preparatory fieldwork lectures. Interested participants were provided with a short information sheet detailing the aims and objectives of the project, their role within it and when they would be required to participate. Consent forms were distributed and signed before the participants completed the questionnaires. Post-trip surveys were dispersed in the same manner at the end of the fieldtrip as the students prepared to return to the UK. The response rates were uneven with 74 pre-trip and 100 post-trip surveys returned in 2015 and 95 pre-trip and 61 post-trip surveys being completed in 2016.

\section{[Insert Table 1 here]}

\section{Results}

\section{Cognitive and affective skills}

Table 2 outlines how the skills obtained by the participants were affected by tropophilia and how these relate to Krathwohl et al's. (1964) taxonomy of learning. These will be referred to in greater detail throughout the rest of the analysis. 
Table 3 reveals differences in perceptions of what cognitve and affective skills the students expected to gain through participating in fieldwork. Before the trips, between $60 \%$ and $78 \%$ (2015) and $71 \%$ and $90 \%$ (2016) of respondents selected the cognitve skills of observation and interpretation, research methods, independent thinking and testing theories and concepts in the field as important attributes to gain from fieldwork. This is commensurate with the stage of the students' degrees (semester two of year two) and reflects the subject-specific skills the students expected to be exposed to as they formulated their dissertation research proposals. Both cohorts reported having previously attended fieldtrips in their pre-trip surveys (99\% (2015) and 98\% (2016)), yet the pedagogic connections between these experiences and their imminent fieldwork were low. Between 55\% (2015) and 68\% (2016) responded 'no' to the question 'Have your previous fieldwork experiences influenced how you might approach this trip?, suggesting some of the respondents had not made the connection between their prior knowledge and the task they were about to commence. This suggests that before the trip many of the students were capable of moving through stages one (receiving) and two (responding) of Krathwohl et al's. (1964) affective learning model with a degree of simplicity, learning how to implement skills in a practical sense. These skills were mirrored in the learning outcomes of the fieldwork module which were very much focused on skilling up on the applied geographies of the trip. In contrast, there were far lower expectations that fieldwork might provide students with affective skills with between $28 \%$ and $40 \%$ (2015) and $34 \%$ and $55 \%$ (2016) of respondents considering understanding local cultures, spatial perception, understanding the bigger 'geographical' picture, exploring interconnections of geographical processes and gaining respect for nature and the environment to be important acquired skills. This is interesting as these are the types of geographical skills that encourage students to think laterally across different modules, rather than considering assessments 
as discrete entities. This is particularly problematic when considering the low expectations among the cohort of skills such as understanding the bigger 'geographical' picture (40\% (2015) / 54\% (2016)), exploring interconnections of geographical processes (29\% / 54\%) and spatial perception (28\% / 34\%) are fundamental field-skills. Crucially though, these affective skills are not necessarily so easy for students to recognise than the more practical cognitve skills of observation and interpretation (78\% / 84\%) and research methods (76\% / 90\%) that often have measurable outcomes and may require field discussions and / or self-reflexive diaries to tease them out more usefully.

\section{[Insert Table 3 here]}

When examining the post-trip data the influence of tropophilia begins to emerge more clearly (Table 3), with a considerable reduction in the contrasts between how the respondents considered the cognitve and affective skills they learned from the trip. Ninetyeight per-cent of the respondents from each year reported their field experiences living up to expectations, suggesting the trip had at least fulfilled the learning outcomes of the module by exposing the students to the practical skills they expected to engage with. Between $69 \%$ and $83 \%(2015)$ and $56 \%$ and $85 \%$ (2016) of the students felt they had gained the cognitive skills of observation and interpretation, research methods, independent thinking and testing theories and concepts in the field, and this reflected the pre-trip expectations:

"It was very insightful and I feel like I have gained a lot of practical skills from completing fieldwork and research which will be valuable for my dissertation." (Posttrip \#31, 2015)

"The trip helped prepare me for my dissertation and reflect on the process of data collection. It was hugely useful, particularly in organisation skills." (Post-trip \#7, 2016) 
These comments indicate stages three (valuing) and four (organising) of the affective learning model in that the participants were appraising the value of their newly acquired knowledge and could imagine the benefits of applying it to other learning scenarios. Moreover, the affective skills of spatial perception, understanding the bigger 'geographical' picture, exploring interconnections of geographical processes and gaining respect for nature and the environment also increased to between $48 \%$ and $69 \%$ (2015) and $66 \%$ and 74\% (2016), bringing them more in-line with the cognitive skills they had expected to gain. Universally, the percentage of respondents choosing affective skills increased, often by around $20 \%$, indicating that the act of 'being in the field' may contribute towards understanding how these less-tangiable skills might be both acknowledged, acquired and given importance. This suggests that the students' learning was stimulated and challenged by the trip. The influence of tropophilia upon learning was clearly evident in the quailtative responses:

"It was amazing to see our projects come to life!" (Post-trip \#36, 2016)

"Opened up new areas of interest and ability to uncover hidden knowledge." (Posttrip \#97, 2015)

These comments suggest fieldwork to be almost revelatory, stimulating tropophilia that both 'bring[s] subjects to life' and 'uncover[s] hidden knowledge' and demonstrates how tropophilic people-place connections provide pedagogic value to fieldwork experiences. The students here appeared to desire a tangiable advancement in knowledge production from attending the field-course. Hence, these tropophilic experiences mean more than simply appraising the field environment and demonstrate how developing affective learning early on in the fieldwork preparation mitigates tropophobia that may detach students from the perceived benefits of fieldwork. Similar to Anderson and Erskine's (2014) idea that "getting away [is] good" (p. 137), the connections between learning about 
fieldwork are firmly couched within learning through being in the field itself and the development of associated skills. These tropophilic links to the affective domain therefore demonstrate some of the practical considerations for applying affective learning in the field by encouraging students to (1) challenge how and where their knowledge is produced and disseminated through their curriculum, (2) question their positionality as learners in transition and (3) encourage students to connect complex geographical processes together.

\section{Student and staff-led projects}

The acquisition of affective tropophilic skills can be explored further by examining the respondents' interpretations of cognitive and affective skills according to the staff-led and student-led projects they completed on the trip (Table 4). Differences emerged between the cohorts in their expectations of the trip and their actual experiences of it. For example, the pre-trip responses reported a greater interest in student-led projects (72\% (2015) and $67 \%$ (2016) respectively). For the 2015 survey this reversed once the post-trip surveys were completed with $68 \%$ preferring the staff-led days, however this was not consistent between the years with $69 \%$ of respondents preferring their student-led projects in 2016 .

Exploring cognitive and affective skills according to those who preferred student-led projects reveals consistencies with the previous analysis. Those preferring the student-led projects considered the cognitive skills of observation and interpretation and research methods among the most important field-skills to develop. This was echoed in the qualitative responses:

"It enabled me to become more independent as a geographer in terms of research through practice and the projects were good for immersing in French culture" (Posttrip, \#12, 2016). 
"I learned a lot about methods and I feel very prepared for my project reports as the methods and theories were put into practice directly in the field" (Post-trip, \#43, 2015).

These comments suggest student-led fieldwork is approached pragmatically through applying research methods and learned knowledge to fieldwork projects rather than considering what being in the field might add to their overall experience, or what skills might be developed beyond the remit of the module. One quarter of respondents in the 2015 post-trip survey and one third of respondents of the 2016 post-trip survey felt the skills learned on the trip would not be useful for their dissertations emphasising the nonlinearity of the affective learning taxonomy. Small variations were present among the other cognitive categories in how the students reported their expectations and experiences of these skills, with the exception of independent thinking, which rose by $17 \%$ between the 2015 pre-trip and post-trip surveys. Conversely, the affective skills perceived or experienced by those preferring student-led projects increased quite dramatically with exploring the interconnections between geographical processes more than doubling for both 2015 and 2016 cohorts. These increases were apparent across all variables (with the exception of understanding local cultures which decreased for both years) and again reflect how students' capacity to learn can be stimulated through engagement and personal connections with field locations. As Simm and Marvell (2015) suggest, this type of learning is commutable, presenting 'in-between' spaces (e.g. travel times or down-time in accommodation) as useful opportunities to pause, reflect and plan. Crucially though, the incongruity of the decrease in understanding local cultures may have less to do with the field experiences themselves and perhaps might instead reflect Nairn's (2005) caution that inexperienced undergraduate researchers may not easily be able to reconcile (or indeed recognise) their own positionality as Other in field-class situations. Notwithstanding, students may also experience mild culture shocks during short fieldwork exercises 
meaning without careful monitoring through informal discussion - cautioned by Simm and Marvell (2015), students can become tropophobic, quickly disengaging and detaching their learning from the field itself if they feel out of place.

[Insert Table 4 here]

Moreover, the staff-led project analysis (Table 4) reveal similarities to the student-led projects in terms of cognitive skills with only small increases and decreases between the categories, with the exception of testing theories and concepts in the field which reported a $15 \%$ increase between the 2015 surveys and a 25\% decrease between the 2016 surveys. Like the student-led projects, staff-led days appeared to increase the potential for gaining affective skills, with noteworthy increases across all categories. The exception here was understanding local cultures which decreased by $43 \%$ between the 2015 surveys, again indicating similar tensions to those mentioned previously. The qualitative responses expand on this by suggesting the structured nature of staff-led days made it easier to make connections between different geographical themes:

"I liked the structure of the staff-led projects. They developed concepts introduced in lectures e.g. planning / social and cultural which I found very interesting and useful for my dissertation proposal." (Res \#18, Post-trip 2015)

"[The] staff-led days were a new experience in areas I had not previously studied and being introduced to them in Ireland was refreshing and stimulating." (Res \#12, Post-trip 2016)

"I took the opportunity to participate in days which weren't immediately related to my studies. Both days were useful for putting lectures into practice in terms of using theory. It was also useful to use different methods of data collection to gain better understandings of the study area." (Res \#36, Post-trip 2015) 
These comments indicate how the staff-led projects encouraged some of the students to consider stage five (internalising) of the affective learning taxonomy more reflexively than perhaps their student-led projects did. The respondents were more self-critical about how their knowledge was produced and how this might influence other learning scenarios. This was achieved by reflexively appraising previous modules while considering the effectiveness of channelling field knowledge into future modules, including the dissertation. Here, tropophilia acts as a tool for facilitating critical ways of scaffolding knowledge by encouraging students to start thinking laterally across modules rather than simply focusing on each assessment. Travel (even short trips) can be transformative (e.g. exploring new ways to grow through exposure to new cultures, languages, topographies and climates). Hence while tropophilia 'refreshes' and challenges received knowledge, the freedom to experiment away from the structures of the classroom appears to give sustainability to such knowledge, while providing confidence to reintroduce skills, experiences and understandings learned in the field back into their curriculum.

\section{Discussion and Conclusion}

This research aimed to examine (1) students' abilities to recognise how affective skills may influence the types of knowledge(s) that are produced on fieldtrips and (2) by what means people-place connections may be capable of inspiring students to become more selfreflexive about their position(s) as learners. Through this exploration of affective learning through tropophilia this research has uncovered incongruities in the approaches students take to acquiring and operationalising knowledge and skills during fieldwork. While research has championed the immersive qualities of active approaches in developing strong cognitive and affective understanding (Boyle et al., 2007; Hope, 2009; Marvell et al., 2013), this analysis demonstrates that acknowledging the role of 'being' in field locations can help produce, scaffold and challenge knowledge while encouraging selfreflexivity among learners. Although Nairn (2005) argues that short bursts of field activity 
are unlikely to be capable of altering students' preconceptions and attitudes, incorporating Anderson and Erskine's (2014) tropophilia highlights how understandings of learning outcomes may be stimulated and reinforced through actively being in the field. Before each trip the students had preconceived expectations of the practical skills required to complete assessment through past experiences and assessment guidelines. While we should be cautious of the epistemological challenges of fieldwork, the research here demonstrates that once in the field students' preconceptions were either reinforced or reconfigured through interactions between people and place (the field site, colleagues and academic staff etc.). Hence, such tropophilic notions deepen Hope's (2009) understandings of the emotional responses experienced by students undertaking fieldwork. Whilst a week-long residential fieldtrip is unlikely to be life-changing for students, as critiqued by Nairn (2005), these participants certainly alluded to revelations regarding their capacity to learn and their ability to reflect upon their knowledge through a more critical lens. This tropophilic understanding of fieldwork therefore indicates that the students were capable of recognising the value of accessing and implementing a much broader suite of life-skills than they had perhaps expected to be exposed to before they went on the trip.

Crucially, considering Krathwohl et al's. (1964) affective learning taxonomy through the lens of tropophilia suggests that learning attributes may be appraised differently in the field to the classroom, with students developing certain attitudes and behaviours that extend beyond acquiescence. This encourages learning to move beyond merely the capacity to acquire applied knowledge and facilitates the chance to extend knowledge of students' relationships with places rather than fixating on their knowledge of them. As outlined in the analysis, the opportunity to appraise an environment, to become, even temporarily, connected to, or immersed in, places that are different to home may add intrinsic value to learning that can be repurposed elsewhere. Hence, encouraging self-reflexivity is an 
essential component in fieldwork, particularly when considering how knowledge is received, responded to, valued, organised and internalised at all stages of the learning experience (Buissink-Smith et al., 2011). This was observed in the boosted affective skills from the post-trip surveys which highlighted how aesthetic understandings of 'place' may enhance connections between emotions and intellect and demonstrate students' abilities to consider their practice more proactively once in the field.

Moreover, while the participants here could not expect to undergo the level of reinvention experienced by Anderson and Erskine's (2016) travelling participants, their suggestion that travel alters person-place connections has certainly been apparent here. The changes noted in the analysis demonstrate the students' increased capacity to draw on a broader range of skills once they had experienced fieldwork - particularly how being in the field provided space for the participants to experiment more freely with learning away from the structure and stasis of the classroom. Notwithstanding the implementation of tropophilia in itself is conducive of developing more nuanced ways of thinking about learning through being mobile subjects, rather than focusing directly upon the destinations in which fieldwork is to be conducted. Crucially, these skills move beyond the more practical cognitive skills they expected to learn to incorporate a range of affective skills that help enhance their learning experiences. This suggests that while connections between people and place might encourage positive place attachments, in a learning capacity they also have the ability to produce different types of knowledge.

Finally, in practical terms identifying how tropophilia might be stimulated by the acquisition of affective field-skills presents interesting opportunities for programme / module leaders who utilise fieldwork in their teaching. McCune and Hounsell (2005) posit how students' engagement with a topic may be enriched by recognising the complex 'ways of thinking and practising' (p. 257) that constitute high-quality learning. How students experience and communicate their knowledge is fundamental in successful engagement with fieldwork and 
encouraging students to explore more creative ways of developing the affective domain prior to entering the field is an excellent way of accomplishing this. This might be achieved though engaging with virtual fieldtrips (Maskall et al., 2007) or past testimonials to help kick-start the development of learners' affective relationship with a field site well before the fieldwork actually commences, thus encouraging the empowerment (Marvell et al., 2013); responsibility (Pawson and Teather, 2002) and transferable skills (Wall and Speake, 2012) necessary for future independent work. However, this may be implemented, accessing affective learning through a more effective appreciation of the field site can only help bolster opportunities to develop broad and sustainable skills.

\section{References}

Anderson, J. (2015). Understanding cultural geography: places and traces. London: Routledge.

Anderson, J., \& Erskine, K. (2014). Tropophilia: a study of people, place and lifestyle travel. Mobilities, 1, 130-145.

Anderson, J., \& Erskine, K. (2016). Lifestyle travel, tropophila and identity transformation.

In G. Lean., R. Staiff., \& E. Waterton (Eds) Travel and Transformation (pp. 29-42). London: Routledge.

Biggs, J., \& Tang, C. (2011). Teaching for quality learning at university: What the student does. Maidenhead, Berkshire: McGraw-Hill Education.

Bloom, B.S. (1956). Taxonomy of educational objectives: The classification of educational goals: Handbook 1, cognitive domain. London: Longman. 
Bolin, A.U., Khramtsova, I., \& Saarnio, D. (2005). Using student journals to stimulate authentic learning: balancing Bloom's cognitive and affective domains. Teaching of Psychology, 32, 154-159.

Boyle, A., Maguire, S., Martin, A., Milsom, C., Nash, R., Rawlinson, S., Turner, A., Wurthmann, S., \& Conchie, S. (2007). Fieldwork is good: The student perception and the affective domain. Journal of Geography in Higher Education, 31, 299-317.

Brew, A. (2006). Research and teaching: beyond the divide. Basingstoke, Hampshire: Palgrave Macmillan.

Buissink-Smith, N., Mann, S., \& Shephard, K. (2011). How do we measure affective learning in higher education? Journal of Education for Sustainable Development, 5, 101114.

Dewey, J. (2007). Experience and education. New York, NY: Touchstone.

Dummer, T.J., Cook, I.G., Parker, S.L., Barrett, G.A., \& Hull, A.P. (2008). Promoting and assessing 'deep learning' in geography fieldwork: An evaluation of reflective field diaries. Journal of Geography in Higher Education, 32, 459-479.

Fuller, I.C. (2006). What is the value of fieldwork? Answers from New Zealand using two contrasting undergraduate physical geography field trips. New Zealand Geographer, 62, 215-220.

Fuller, I., Edmondson, S., France, D., Higgitt, D., \& Ratinen, I. (2006). International perspectives on the effectiveness of geography fieldwork for learning. Journal of Geography in Higher Education, 30, 89-101.

Gibbs, G. (1992). Improving the Quality of Student Learning. Oxford: Oxford Centre for Staff Development. 
Glass, M.R. (2015). International geography field courses: practices and challenges. Journal of Geography in Higher Education, 39 485-490.

Gold, J.R., Jenkins, A., Lee, R., Monk, J., Riley, J., Shepherd, I. \& Unwin, D. (1991). Teaching geography in higher education: a manual of good practice. Oxford: Blackwell.

Hay, R. (1998). Sense of place in developmental context. Journal of Environmental Psychology, 18, 5-29.

Herrick, C. (2010). Lost in the field: ensuring student learning in the 'threatened' geography fieldtrip. Area, 42, 108-116.

Hope, M. (2009). The importance of direct experience: A philosophical defence of fieldwork in human geography. Journal of Geography in Higher Education, 33, 169-182.

Katz, C. (1994). Playing the field: questions of fieldwork in geography. The Professional Geographer, 46, 67-72.

Kent, M., Gilbertson, D.D., \& Hunt, C.O. (1997). Fieldwork in geography teaching: A critical review of the literature and approaches. Journal of Geography in Higher Education, 21, 313-332.

Kolb, D.A. (1984). Experiential learning: Experience as the source of learning and development (Vol. 1). Englewood Cliffs, NJ: Prentice-Hall.

Krathwohl, D.R., Bloom, B.S., \& Masia, B.B. (1964). Taxonomy of educational objectives:

The classification of educational goals: Handbook 2, Affective domain. London: Longman.

McCune, V., \& Hounsell, D. (2005). The development of students' ways of thinking and practising in three final-year biology courses. Higher Education, 49, 255-289. 
Mcguinness, M., \& Simm, D. (2005). Going global? Long-haul fieldwork in undergraduate geography. Journal of Geography in Higher Education, 29, 241-253.

Marvell, A., Simm, D., Schaaf, R., \& Harper, R. (2013). Students as scholars: evaluating student-led learning and teaching during fieldwork. Journal of Geography in Higher Education, 37, 547-566.

Maskall, J., Stokes, A., Truscott, J.B., Bridge, A., Magnier, K., \& Calderbank, V. (2007). Supporting fieldwork using information technology. Planet, 18, 18-21.

Nairn, K. (2005). The problems of utilizing 'direct experience' in geography education. Journal of Geography in Higher Education, 29, 293-309.

Panelli, R., \& Welch, R.V. (2005). Teaching research through field studies: a cumulative opportunity for teaching methodology to human geography undergraduates. Journal of Geography in Higher Education, 29, 255-277.

Pawson, E., \& Teather, E.K. (2002). 'Geographical Expeditions': Assessing the benefits of a student-driven fieldwork method. Journal of Geography in Higher Education, 26, 275289.

Phillips, R., \& Johns, J. (2012). Fieldwork for human geography. London, SAGE.

Punch, K.F. (2014). Introduction to social research: Quantitative and qualitative approaches. London, Sage.

Scheyvens, R., Griffin, A.L., Jocoy, C.L., Liu, Y., \& Bradford, M. (2008). Experimenting with active learning in geography: Dispelling the myths that perpetuate resistance. Journal of Geography in Higher Education, 32, 51-69. 
Scott, I., Fuller, I., \& Gaskin, S. (2006). Life without fieldwork: Some lecturers' perceptions of geography and environmental science fieldwork. Journal of Geography in Higher Education, 30, 161-171.

Simm, D., \& Marvell, A. (2015). Gaining a "sense of place": students' affective experiences of place leading to transformative learning on international fieldwork. Journal of Geography in Higher Education, 39, 595-616.

Secor, A.J. (2010). Social surveys, interviews and focus groups. In B. Gomez, \& J.P. Jones III (Eds) Research Methods in Geography: A Critical Introduction (pp. 194-203). Oxford: Wiley-Blackwell.

Spronken-Smith, R., \& Hilton, M. (2009). Recapturing quality field experiences and strengthening teaching-research links. New Zealand Geographer, 65, 139-146.

Stokes, A., Magnier, K., \& Weaver, R. (2011). What is the use of fieldwork? Conceptions of students and staff in geography and geology. Journal of Geography in Higher Education, 35, 121-141.

Tuan, Y.F. (1974). Topophilia: A study of environmental perceptions, attitudes, and values. Chichester, West Sussex: Columbia University Press.

Van der Hoeven Kraft, K.J., Srogi, L., Husman, J., Semken, S., \& Fuhrman, M. (2011). Engaging students to learn through the affective domain: a new framework for teaching in the geosciences. Journal of Geoscience Education, 59, 71-84.

Wall, G.P., \& Speake, J. (2012). European geography higher education fieldwork and the skills agenda. Journal of Geography in Higher Education, 36, 421-435. 


\section{Captions:}

Table 1: Question design for each of the pre-trip and post-trip surveys.

Table 2: The influence of tropophilia on affective learning attributes and its potential application in practice (adapted from Buissink et al. (2011, p. 105) and author's own data).

Table 3: Combined comparative percentage results of the pre-trip and post-trip surveys for both 2015 and 2016.

Table 4: Comparative percentage results for the pre-trip and post-trip survey responses according to the respondents' preferences for their student-led and staff-led projects. 